\title{
Nonlinear mechanics study of concrete t-beam bridge with cracking damage based on numerical simulation
}

\author{
PULU HAN \\ Inner Mongolia University of Science \& Technology, \\ Baotou, Inner Mongolia 014010, CHINA
}

Received: April 29, 2020. Revised: June 19, 2020. Accepted: June 23, 2020. Published: June 24, 2020

\begin{abstract}
The cracking damage of concrete bridge will seriously affect the overall safety of a structure. In this study, based on the numerical simulation, finite element analysis was carried out on the concrete $\mathrm{T}$ beam through the ANSYS software, and the selection of elements and the constitutive relationship of materials in the numerical simulation were introduced. It was found from the results of numerical simulation that the cracks of $\mathrm{T}$ beam continued to develop under the action of load, the concrete entered the plastic state from the elastic state and the mid-span deflection increased with the increase of load. In the case of the change of cracks, the larger the crack height, the larger the crack range of the beam. With the increase of load, the structural rigidity continued to degenerate, and the compressive stress of the concrete also increased. The research in this paper proves the validity of numerical simulation in the study of nonlinear mechanics of beam bridge and also makes some contributions to the study of crack damage of beam bridge.
\end{abstract}

Keywords - Cracking damage, finite element analysis, numerical simulation, nonlinear mechanics, $\mathrm{T}$ beam.

\section{INTRODUCTION}

$I_{v}^{N}$ $\mathrm{N}$ bridge engineering, concrete structure is widely used [1]. With the development of economy, the number of beam bridges is increasing, the traffic volume is also increasing, and the large-tonnage heavy vehicles are also become more and more, which brings great pressure to beam bridges. The construction of beam bridge facilitates people's travel and promotes economic development. However, once there is an accident of beam bridge, it will cause a huge impact, which will cause great economic loss and may endanger people's life safety. Therefore, it is of great significance to monitor and analyze the damage of beam bridge. $\mathrm{T}$ beam has been widely used in beam bridges, and its performance in various aspects has also been widely concerned by researchers. Hag-Elsafi et al. [2] studied the application of fiber-reinforced polymer (FRP) composite laminate in the reinforcement of aging reinforced concrete T-beam bridges, carried out load test, and analyzed its influence on the structural performance. Hawileh et al. [3] studied the fire resistance of $\mathrm{T}$ beams strengthened with carbon fiber reinforced polymer (CFRP), analyzed using the finite element model in ANSYS, compared it with the actual situation, and found that the simulation results were highly consistent with the actual results. Zhu et al. [4] studied the fatigue performance of $T$ beam. Through the constant amplitude fatigue load test of five $T$ beams, they found found that the fatigue damage developed rapidly in the early and late stage of the test and almost all the cracks stopped growing when the beam broke. Xie et al. [5] studied the damage and aging of $T$ beams based on the finite element model by using the flexibility difference method and damage indication criterion, revealed the damage detection characteristics, and put forward some suggestions. Sasaki et al. [6] conducted a detailed evaluation on 12 five-girder T-beam bridges on I-40 in the southwest of the United States, determined several failure factors, including high volume of heavy truck traffic, wheel load imbalance, etc., and proposed that special inspection should be carried out for construction joints in the beam bridge. Numerical simulation method has a good application in structural analysis. Based on the complete Lagrangian method, Mokhatar et al. [7] analyzed the response of the beam under impact load through numerical simulation and simulated the influence of the low-speed impact on the beam structure. Kataoka et al. [8] pointed out that numerical simulation could obtain some information about structural stress, displacement, strain, etc., which could not be obtained by experiments, so as to better understand structural behavior. Kozlowski et al. [9] carried out numerical research on the fracture behavior of the beam by the extended finite element method and carried out reliable calculation on the bearing 
capacity and damage mechanism of the beam, which provided some bases for the application of the structure in practice. Braun et al. [10] analyzed the performance of beams with concrete pins by numerical simulation and found that the material had better stiffness and ductility and more economic advantages compared with beams with traditional shear bolts. In this study, based on the numerical simulation, the nonlinear analysis of concrete $\mathrm{T}$ beam was carried out by ANSYS software, in order to find out the performance change rule of $\mathrm{T}$ beam with cracking damage. This study can provide a powerful evidence for determining the actual carrying capacity of $\mathrm{T}$ beam and important guidance for the maintenance and reinforcement of beam bridges. Moreover the experiment also verified that the numerical simulation method was effective in the non-linear mechanical analysis of beam bridges and it made up the shortcomings of high cost, multiple limitations and incapability of performing large-scale destructive test in the model experiment.

\section{CRacking Damage of Concrete T-Beam Bridge}

Concrete is a kind of heterogeneous material, which has defects such as cracks [11], bubbles, cavities [12], etc. Due to the high compressive strength and low tensile strength, cracks are easy to form in concrete. The cracking damage of concrete is caused by cracks, and the process is as follows.

(1) At the initial stage of stress, the microcracks in the structure are stable.

(2) With the increase of load, microcracks begin to develop and extend into cement paste.

(3) The small cracks overlap and run through each other to cut apart the cement stone, and then the structure loses elasticity and is in a non-linear stress state.

(4) Cracks develop to the surface of the structure, forming cracks visible to the naked eye.

(5) As the load continues to increase, the crack continues to develop, and its number, height and width increase, resulting in structural fracture.

The cracks which form under load are only a small part, and most of cracks are caused by volume shrinkage of concrete, forced displacement caused by earthquake or settlement, long-term salt cold environment [13, 14], steel corrosion [15], improper construction, structural fatigue [16], etc., which are difficult to avoid.

$\mathrm{T}$ beam has been widely used in bridge engineering. It has light weight and simple construction. It has good application in urban road bridges and highway bridges. In the service process, it is found that many bridges have the problem of cracking damage, which directly affects the structural safety. Therefore, the analysis of the mechanical properties of the cracked structure has a very important practical value. In the current research of structural performance, professional technicians can check the appearance of the structure, or the working condition of the structure can be measured through load test. However, the appearance inspection has strong subjectivity and higher professional requirements for technicians. Although the load test method has high precision, it is difficult to carry out in large scale and takes a lot of human, material and financial resources. Although the numerical simulation method can only reflect the mechanical properties of the real bridge to a certain extent, compared with the load test, it is less limited and can realize the whole process of the structure from stress to failure, which shows a good performance in the structural analysis. Thus, based on the numerical simulation, the nonlinear mechanical properties of $\mathrm{T}$ beam with cracking were analyzed in this study.

\section{PROBlem SOLUTION}

\section{A. Experimental Study on Concrete T-beam Bridge with Cracking Damage}

The concrete $\mathrm{T}$ beam model is shown in Fig. 1. The concrete was C50, the measured compressive strength was $52.4 \mathrm{MPa}$, and the elasticity modulus was $4.85 \times 10^{4} \mathrm{MPa}$; the steel bar was HRB335, the yield strength was $345 \mathrm{MPa}$, and the elasticity modulus was $1.68 \times 10^{5} \mathrm{MPa}$. To obtain the change of mechanical properties of $\mathrm{T}$ beam, strain gauges were arranged on the $\mathrm{T}$ beam, as shown in Fig. 2.

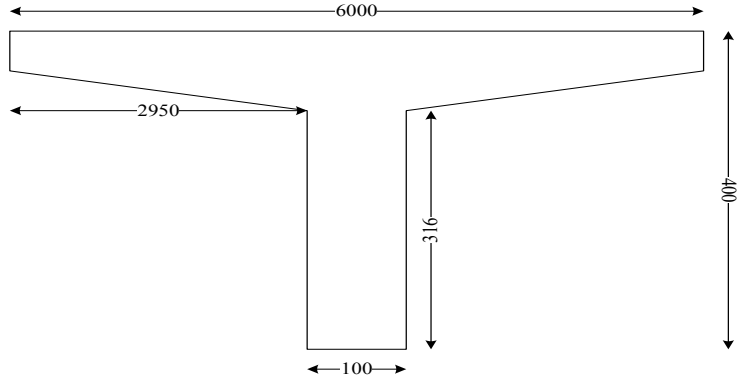

Fig. $1 \mathrm{~T}$ beam model

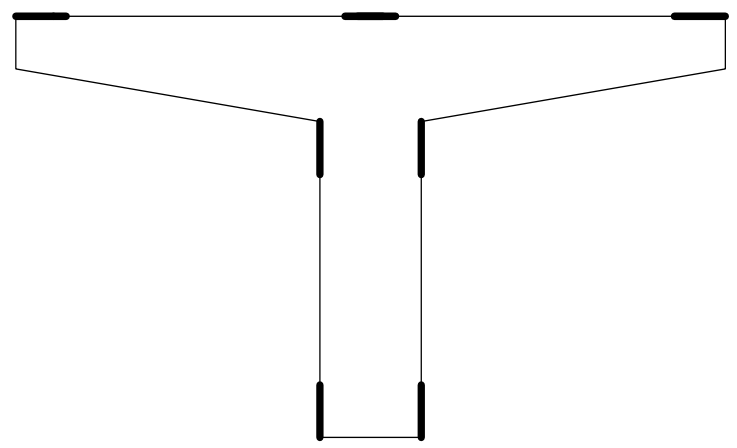

Fig. 2 The arrangement of strain gauges

The generation and growth of T-beam cracks were observed by a crack width gauge. Load was applied grade by grade with an increment of $5 \mathrm{kN}$ by means of one-third loading mode until the test specimen failed. Corresponding data were collected and recorded after the application of every grade of load became stable.

\section{B. Nonlinear Finite Element Numerical Simulation of T Beam}

The difference between the tensile strength and compressive strength of concrete T-beams is large. After cracking, the flexural members will enter into a nonlinear state, and the other 
properties of the structure such as deformation will change. With the development of finite element technology, the theory has been able to carry out accurate analysis of the structure with cracking. In this study, numerical simulation was carried out on the $T$ beam using ANSYS [17]. It was assumed that the displacement of the contact surface between steel bar and concrete was coordinated, bonding slip was not considered, and the deformation of concrete induced by shrinkage and creep was ignored.

(1) Element selection

Nonlinear element Solid65 was used as the concrete [18], which fully considered the nonlinear characteristics of the structure and had a high simulation accuracy for cracking damage. Solid65 unit has eight nodes, each of which has freedom degrees in $\mathrm{x}, \mathrm{y}$ and $\mathrm{z}$ directions. See Table 1 for parameters.

Link 8 element [19] was used as the steel bar, which has large deformation and large strain and is plastic. Each element has two nodes, each node has three freedom degrees in $\mathrm{x}, \mathrm{y}$ and $\mathrm{z}$ directions. see Table 1 for parameters.

Table 1 Specific parameters of the structure

\begin{tabular}{|l|l|l|}
\hline & Concrete & Steel bar \\
\hline Poisson's ratio & 0.2 & 0.3 \\
\hline $\begin{array}{l}\text { Compressive } \\
\text { strength/MPa }\end{array}$ & 32.5 & 400 \\
\hline $\begin{array}{l}\text { Tensile } \\
\text { strength/MPa }\end{array}$ & 2.7 & 335 \\
\hline
\end{tabular}

(2) Material constitution

The constitutive model of concrete adopts the Hongnestad formula:

$$
\left.\begin{array}{c}
\lambda=\lambda_{0}\left[2\left(\frac{\gamma}{\gamma_{0}}\right)-\left(\frac{\gamma}{\gamma_{0}}\right)^{2}\right], \gamma \leq \gamma_{0} \\
\lambda=\lambda_{0}\left[1-0.15\left(\frac{\gamma-\gamma_{0}}{\gamma_{u}-\gamma_{0}}\right)\right], \gamma<\gamma_{0}<\gamma_{u}
\end{array}\right\},
$$

where $\lambda$ and $\gamma$ stand for stress and strain respectively, $\lambda_{0}$ and $\gamma_{0}$ stand for the standard value of axial compressive strength and its strain respectively, and $\gamma_{u}$ stands for the ultimate compressive strain.

The failure criterion of concrete can be expressed as:

$$
\frac{F}{f_{c}}-C \geq 0
$$

where $F$ stands for the principal stress function, $f_{c}$ stands for the uniaxial compressive strength, and $C$ stands for the failure surface.

The steel bar adopts the ideal elastic-plastic constitutive model, which is expressed as follows:

$$
\text { when } 0 \leq \gamma_{s} \leq \gamma_{y}, \lambda_{s}=\gamma_{s} Y_{s} \text {, }
$$$$
\text { when } \gamma_{s} \geq \gamma_{y}, \lambda_{s}=f_{y} \text {, }
$$

where $\lambda_{s}$ and $\gamma_{s}$ represent the ultimate strength and ultimate strain, $\gamma_{y}$ represents the yield strain, $Y_{s}$ represents the modulus of elasticity, and $f_{y}$ represents the yield strength.

(3) Prestress simulation

The initial stress method, initial strain method and cooling method can be used to simulate prestress. In this study, the initial strain method was used. Before the application of external applied load $W$, an initial strain value was added to the strain matrix of prestressed reinforcement, which can be expressed as:

$$
\gamma=\frac{F}{F+S E}
$$

where $\gamma$ stands for the initial strain, $F$ stands for the initial tension, and $S$ stands for the area of prestressed reinforcement.

(4) Other conditions

In order to simplify the calculation, a $1 / 2$ symmetric model was used in the modeling. There were 30251 Solid65 elements and 225 Link 8 elements in the model. When loading, the dead load was automatically applied by the program, and $P=K \cdot J=\alpha \cdot \beta \cdot J$ was taken as the live load, where $K$ is the load factor, $\alpha$ is the correction coefficient of live load influence under overload, $\beta$ is the load transverse distribution coefficient, and $J$ is the reference load.

\section{Analysis of Numerical Simulation Results}

(1) Load-deflection curve

The mid-span deflection change of the T-beam section is as shown in Fig. 3.

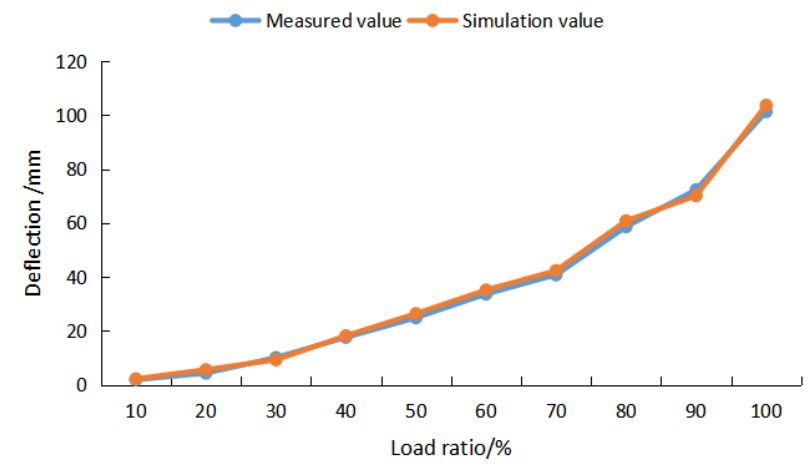

Fig. 3 The load-deflection curve

Table 2 The simulated value of deflection

\begin{tabular}{|c|c|c|c|c|c|c|c|c|c|c|}
\hline $\begin{array}{c}\text { Load } \\
\text { ratio/ } \\
\%\end{array}$ & 10 & 20 & 30 & 40 & 50 & 60 & 70 & 80 & 90 & $\begin{array}{c}10 \\
0\end{array}$ \\
\hline
\end{tabular}




\begin{tabular}{|l|c|c|c|c|c|c|c|c|c|c|}
\hline Error & 0. & 1. & 0. & 0. & 1. & 1. & 1. & 2. & 2. & 2. \\
$/ \mathrm{mm}$ & 32 & 26 & 81 & 58 & 53 & 50 & 54 & 17 & 21 & 36 \\
\hline
\end{tabular}

It was seen from Table 2 that the result of the numerical simulation coincided well with the test results, with small errors. The errors included idealization error caused by some necessary simplification in the establishment of physical model and numerical error caused by the numerical calculation. It was seen from Fig. 3 that the deflection change of T-beam was roughly divided into three stages: in the first stage, the concrete had no crack and was in the elastic state, and the deformation was very small; in the second stage, the beam cracked and was in the elastic-plastic stage, and the rigidity of the beam decreased and the deformation of the beam continued to develop as the cracks continued to develop; in the third stage, the steel bars yielded and entered the plastic state, and the deformation continued to increase and the deflection increased rapidly as the concrete has been crushed.

(2) Crack changes

The change of T-beam crack is shown in Fig. 4.

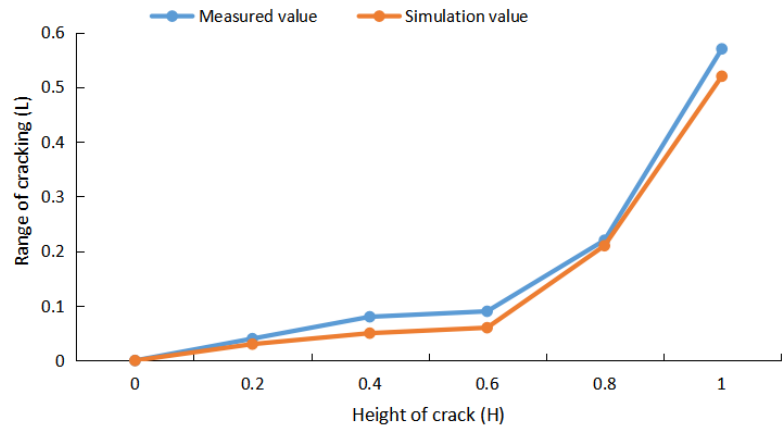

Fig. 4 Change of T-beam crack
The simulation error of crack change is shown in Table 3.

Table 3 The simulated error of crack change

\begin{tabular}{|c|c|c|c|c|c|c|}
\hline $\begin{array}{c}\text { Crack } \\
\text { height }\end{array}$ & 0 & 0.2 & 0.4 & 0.6 & 0.8 & 1.0 \\
\hline Error & 0 & 0.01 & 0.03 & 0.03 & 0.01 & 0.05 \\
\hline
\end{tabular}

In Fig. 4, $\mathrm{L}$ refers to the span of the beam, and $\mathrm{H}$ refers to the height of the beam. It was seen from Fig. 4 that the crack height developed continuously and the crack range also increased continuously with the increase of the load; before the crack height was $0.6 \mathrm{H}$, the crack range of the beam was still small; when the crack height reached $0.8 \mathrm{H}$, the crack range increased rapidly; when the crack height was $0.6 \mathrm{H}$, the crack range was still smaller than $0.1 \mathrm{~L}$; when the height of the crack reached 0.8 $\mathrm{H}$, the cracking range was larger than $0.2 \mathrm{~L}$; when the crack reached $1 \mathrm{H}$, the cracking range was larger than $0.5 \mathrm{H}$, which indicated that the T-beam has been seriously damaged and the performance of the beam has been greatly degraded. Peng [20] also found through experimental study that the crack opening displacement was proportional to the load, i.e., the crack grew with the increase of load, which was similar to the result of this study.

(3) Stiffness degradation

The stiffness degradation of T-beam under different loads is shown in Table 4.

Table 4 Degradation coefficients of T-beam rigidity

\begin{tabular}{|c|c|c|c|c|c|}
\hline \multicolumn{2}{|c|}{ Crack height $(\mathrm{H})$} & $\mathrm{K}=0.45$ & $\mathrm{~K}=0.50$ & $\mathrm{~K}=0.55$ & $\mathrm{~K}=0.60$ \\
\hline 0.1 & $\begin{array}{c}\text { Measured } \\
\text { value }\end{array}$ & 1 & 0.97 & 0.93 & 0.91 \\
\cline { 2 - 6 } & $\begin{array}{c}\text { Simulated } \\
\text { value }\end{array}$ & 1 & 0.99 & 0.95 & 0.94 \\
\cline { 2 - 6 } & Error & 0 & 0.02 & 0.02 & 0.03 \\
\hline 0.2 & $\begin{array}{c}\text { Measured } \\
\text { value }\end{array}$ & 1 & 0.95 & 0.83 & 0.79 \\
\cline { 2 - 6 } & $\begin{array}{c}\text { Simulated } \\
\text { value }\end{array}$ & 1 & 0.97 & 0.87 & 0.85 \\
\cline { 2 - 6 } & Error & 0 & 0.05 & 0.04 & 0.06 \\
\hline 0.3 & $\begin{array}{c}\text { Measured } \\
\text { value }\end{array}$ & 1 & 0.92 & 0.81 & 0.78 \\
\cline { 2 - 6 } & $\begin{array}{c}\text { Simulated } \\
\text { value }\end{array}$ & 1 & 0.95 & 0.86 & 0.84 \\
\cline { 2 - 6 } & Error & 0 & 0.03 & 0.04 & 0.06 \\
\hline \multirow{7}{*}{0.4} & $\begin{array}{c}\text { Measured } \\
\text { value }\end{array}$ & 0.97 & 0.91 & 0.79 & 0.75 \\
\cline { 2 - 6 } & $\begin{array}{c}\text { Simulated } \\
\text { value }\end{array}$ & 0.99 & 0.94 & 0.85 & 0.82 \\
\cline { 2 - 6 } & Error & 0.02 & 0.03 & 0.06 & 0.07 \\
\hline
\end{tabular}




\begin{tabular}{|c|c|c|c|c|c|}
\hline 0.5 & $\begin{array}{c}\text { Measured } \\
\text { value }\end{array}$ & 0.95 & 0.88 & 0.79 & 0.75 \\
\cline { 2 - 6 } & $\begin{array}{c}\text { Simulated } \\
\text { value }\end{array}$ & 0.98 & 0.93 & 0.83 & 0.78 \\
\cline { 2 - 6 } & Error & 0.03 & 0.05 & 0.04 & 0.03 \\
\hline
\end{tabular}

It was seen from Table 4 that the error between the measured value and simulated value was small, the rigidity degeneration was similar. Taking the simulated value as an example, the development of cracks had little influence on the performance of T-beam and the stiffness degradation was small when load factor $\mathrm{K}$ was small; when $\mathrm{K}=0.5, \mathrm{H}=0.5$, the maximum stiffness degradation was $7 \%$, but with the increase of load factor, the growth of cracks had a great impact on the performance of T-beam; when $\mathrm{K}=0.55, \mathrm{H}=0.5$, the stiffness degradation was $17 \%$; when $\mathrm{K}=0.6, \mathrm{H}=0.5$, the stiffness degradation was $22 \%$, which showed that the development of cracks led to a significant decline in the performance of T-beam under the large load.

(4) Change of concrete stress

The stress changes of T-beam concrete under different loads are shown in Fig. 5.

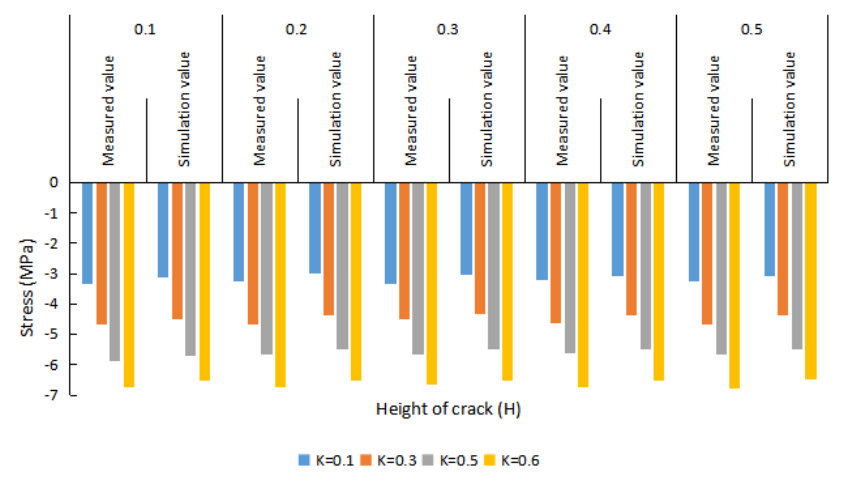

Fig. 5 The change of concrete stress

The simulated error of concrete stress change is shown in Table 5.

Table 5 The simulated error of stress change

\begin{tabular}{|c|c|c|c|c|c|}
\hline Crack height $(\mathrm{H})$ & 0.1 & 0.2 & 0.3 & 0.4 & 0.5 \\
\hline $\mathrm{K}=0.1$ & 0.2 & 0.26 & 0.31 & 0.13 & 0.2 \\
\hline $\mathrm{K}=0.3$ & 0.16 & 0.32 & 0.2 & 0.3 & 0.32 \\
\hline $\mathrm{K}=0.5$ & 0.16 & 0.15 & 0.17 & 0.15 & 0.19 \\
\hline $\mathrm{K}=0.6$ & 0.18 & 0.2 & 0.13 & 0.21 & 0.27 \\
\hline
\end{tabular}

It was seen from Table 5 and Fig. 5 that the measured value coincided well with the simulated value, which was similar to the research result of Zhu [21]. Zhu found through the field test and simulation by SAP2000 software that the field measurement result was highly consistent with the simulation result. It was seen from Fig. 5 that the change of concrete stress was greatly affected by the load; when the load factor was small, the concrete compression was also small; with the increase of load factor, the concrete compression also gradually increased; under the same crack height, taking the simulated value as an example, the stress ratio of concrete when $\mathrm{H}=0.5$ and $\mathrm{K}=0.6$ increased by $112 \%$ compared to that when $\mathrm{K}=0.1$, which showed that the increase of load led to the rapid increase of the compressive stress of concrete after the cracking damage of $\mathrm{T}$ beam.

\section{Discussion}

In the service process of the beam bridge structure, due to reasons such as natural aging [22], vehicle overload [23] and improper maintenance, the problem of cracking exists. Under the action of concrete and steel bars, it has obvious nonlinear effect [24], which will seriously threaten the safe operation of the bridge. Therefore, the research on the performance of the beam bridge with cracking is helpful to judge the function of the existing bridge and predict the bridge structural degradation and reinforcement. Based on ANSYS, the performance of T beam with cracking damage was analyzed. According to the results of numerical simulation, it was found that:

(1) the deflection of T beam increased with the cracking of beam, and it entered the plastic state from the elastic state;

(2) the larger the crack height was, the larger the crack range was;

(3) the larger the load factor, the larger the rigidity degeneration of beam, and the maximum degradation was $22 \%$;

(4) the greater the load factor was, the greater the compressive stress of concrete was.

According to the research results, it was found that the original cracks developed continuously under the action of load and the performance of beam degenerated with the increase of load. This study verifies the effectiveness of numerical simulation method in the performance study of $\mathrm{T}$ beam with cracking damage, which provides some theoretical supports for its application in the nonlinear mechanical analysis of concrete beams. However, there are also some limitations, for example, the research results were not tested on real bridges. In future studies, the performance change of beams will be analyzed, further numerical analysis will be carried out on the cracking damage under factors such as fatigue load and dynamic load, and the real bridge will be experimented to further verify the rationality of the research results.

\section{REFERENCES}

[1] P. Giri, and S. Kharkovsky, "Detection of Surface Crack in Concrete Using Measurement Technique With Laser Displacement Sensor," IEEE T. Instrum. Meas., Vol.65, No.8, pp. 1-3, 2016.

[2] O. Hag-Elsafi, S. Alampalli, and J. Kunin, "Application of FRP laminates for strengthening reinforced concrete T-beam bridge structure," Compos Struct, Vol.52, No.3-4, pp. 453-466, 2001. 
[3] R. A. Hawileh, M. Naser, W. Zaidan, and H. Rasheed, "Modeling of insulated CFRP-strengthened reinforced concrete T-beam exposed to fire," Eng Struct, Vol.31, No.12, pp. 3072-3079, 2009.

[4] H. B. Zhu, Y. Q. Xu, X. Li, and Z. W. Yu, "Fatigue Behavior of Reinforced Concrete T-Beam," J. Highway Transp. Res. Dev., Vol.8, No.3, pp. 46-51, 2014.

[5] J. Xie, and D. J. Han, "Numerical simulation of damage detection for simple-supported reinforced concrete T-beam bridge," China J Highway Transp, Vol.17, No.4, pp. 45-49, 2004.

[6] K. K. Sasaki, T. Paret, J. C. Araiza, and P. Hals, "Failure of concrete T-beam and box-girder highway bridges subjected to cyclic loading from traffic," Eng Struct, Vol.32, No.7, pp. 1838-1845, 2010.

[7] S. N. Mokhatar, Y. Sonoda, S. S. M. Zuki, A. F. Kamarudin, and M. S. Md Noh, "Simulation of Shear and Bending Cracking in RC Beam: Material Model and its Application to Impact," IOP Conf. Ser. Earth Environ. Sci., Vol.140, No.1, pp. 012130, 2018.

[8] M. N. Kataoka, M. Ferreira, A. L. H. de Cresce El Debs, "Nonlinear FE analysis of slab-beam-column connection in precast concrete structures," Eng. Struct., Vol.143, pp. 306-315, 2017.

[9] M. Kozlowski, M. Kadela, and M. Gwozdz-Lason, "Numerical Fracture Analysis of Foamed Concrete Beam Using XFEM Method, Appl. Mech. Mater., Vol.837, pp. 183-186, 2016.

[10] M. Braun, R. Obiala, and C. Odenbreit, "Numerical simulation of the load bearing behaviour of concrete dowels in slim-floor construction CoSFB," Celpapers, Vol.1, No.2-3, pp. 1831-1840, 2017.

[11] T. Barkavi, and C. Natarajan, "Knowledge-based decision support system for identification of crack causes in concrete buildings," Asian J. Civil Eng., Vol.19, No.4, pp. 1-10, 2018.

[12] S. A. Kristiawan, and G. Y. Sunarmasto, Murti, "Porosity of Self-Compacting Concrete (SCC) incorporating high volume fly ash," IOP Conf. Ser. Mater. Sci. Eng., Vol.176, pp. 012043-, 2017.

[13] J. Guo, M. Yang, H. Chen, and J. Han, "Experiment study on fracture properties of modified concrete attacked by sulfate corrosion under dry-wet circulation," J. Hydraul. Eng., Vol.49, No.4, pp. 419-427, 2018.

[14] X. H. Yao, Z. J. Feng, F. C. Wang, Z. H. Xu, N. Liu, and G. B. Yao, "Experiment on erosion-resistance of highway bridge pile foundation material under salt marshes environment," J. Chang'an Univ. (Natl. Sci. Ed.), Vol.38, No.1, pp. 49-58, 2018

[15] X .L. Du, R. B. Zhang, and L. Jin, "Meso-scale numerical investigation on the crack process of concrete cover induced by rebar non-uniform corrosion," J. Civil Archit. Environ. Eng., Vol.37, No.1, pp. 73-80, 2015.

[16] C. V. D. Haar, and S. Marx, "A strain model for fatigue-loaded concrete," Struct. Concrete, Vol.19, No.2, pp. 463-471, 2018.

[17] L. Meng, and M. Mei, "Application of ANSYS optimization methods in design of joint closure temperature of arch dams," J. Hydroel. Eng., Vol.37, No.3, pp. 11-17, 2018

[18] J. Li, "Experiment and ANSYS Finite Element Analysis on Concrete Filled Thin-Walled Steel Tube Joints," Appl. Mech. Mater., Vol.321-324, pp. 234-238, 2013.

[19] G. Vasudevan, and S. Kothandaraman, "Finite Element Analysis of Bearing Capacity of RC Beams Retrofitted with External Bars," Strength Mater., Vol.46, No.6, pp. 831-842, 2014.

[20] D. Peng, "Study on the Mechanical Characteristics of Steel Fiber Reinforced Concrete Crack using Strain Gauges for Structure Health Monitoring," Res. J. Appl. Sci. Eng. Tech., Vol.4, No.22, pp. 4777-4782, 2012.

[21] H. Zhu, "Crack formation of steel reinforced concrete structure under stress in construction period," Frattura ed Integrità Strutturale, Vol.10, No.36, pp. 191-200, 2016.

[22] I. H. Kim, H. Jeon, B. C. Baek, W. H. Hong, and H. J. Jung, “Application of Crack Identification Techniques for an Aging Concrete Bridge Inspection Using an Unmanned Aerial Vehicle," Sensors, Vol.18, No.6, pp. 1881-, 2018.

[23] H. S. Xu, S. Wang, D. H. Yan, and M. Lin, "Analysis model before cable replacement construction of stay cable bridge with time-dependent effects," J. Civil Archit. Environ. Eng., Vol.37, No.4, pp. 45-50, 2015.

[24] F. Iguetoulene, "Non linear modeling of three-dimensional reinforced and fiber concrete structures," Front. Struct. Civ. Eng., Vol.12, No.4, pp. $439-453,2018$.

\section{Creative Commons Attribution License 4.0 (Attribution 4.0 International , CC BY 4.0)}

This article is published under the terms of the Creative Commons Attribution License 4.0 https://creativecommons.org/licenses/by/4.0/deed.en US 